\title{
Analysis of inferior nasal turbinate width and concha bullosa in subjects with nasal septum deviation: a cone beam tomography study
}

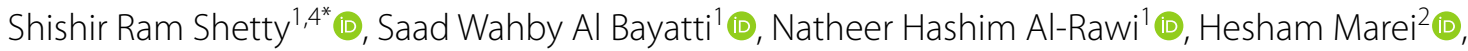

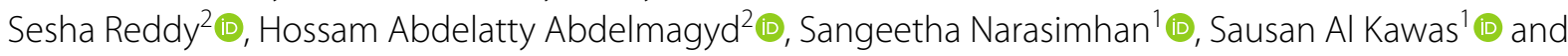
Asok Mathew ${ }^{3}$ (I)

\begin{abstract}
Background: In individuals with nasal septal deviation (NSD), compensatory hypertrophy of the nasal turbinates occurs as a protective mechanism of the nasal passage from dry and cold air. NSD associated nasal turbinate hypertrophy is usually recurrent, requiring repetitive imaging. Therefore, a multiplanar imaging modality with a low radiation dose is best suited for long-term follow-up of this condition. This study aimed to evaluate the association of width of inferior turbinates and presence of concha bullosa with the degree of NSD using Cone beam computed tomography (CT).
\end{abstract}

Methods: The CBCT scans of 100 patients with NSD were selected as per convenience sampling and were evaluated by two maxillofacial radiologists. The width of the non-hypertrophied inferior turbinate (NHT) on the convex side of the NSD, and hypertrophic inferior turbinates $(H T)$ on the concave side of the NSD were measured at three locations. The septal deviation angle (SDA) and the presence of concha bullosa (CB) were determined.

Results: A significant difference was observed in the anterior, middle, posterior, and mean widths between $\mathrm{HT}$ and NHT $(p<0.001)$. There was a significant difference in the widths of the HT and NHT among different types of NSD. A strong positive correlation $(r=0.71, p<0.001)$ was found between SDA and the mean width of the HT. Age $(P=0.71)$ and gender $(P=0.65)$ had no significant difference among different types of NSD. Regression analysis revealed that the presence of CB $(p=0.01)$ and middle width of the HT $(p<0.001)$ are significant predictors of SDA and type of NSD.

Conclusion: The results of the present study reveal that the middle width of the $\mathrm{HT}$ and the presence of $\mathrm{CB}$ influence the degree of NSD. The present study results recommend the use of CBCT as a substitutive low radiation dose imaging modality for evaluation of NSD, CB, and associated inferior turbinate hypertrophy.

Keywords: Nasal septal deviation, Compensatory hypertrophy, Inferior turbinate, Cone beam computed tomography

*Correspondence: shishirshettyomr@gmail.com

${ }^{1}$ College of Dental Medicine, University of Sharjah, Sharjah, United Arab Emirates

Full list of author information is available at the end of the article

\section{Introduction}

Nasal obstruction is one of the commonly reported symptoms in clinical practice [1] . It is estimated that $42 \%$ of the population may have some form of a nasal septal deviation (NSD) and associated compensatory hypertrophy of the nasal turbinate [2] . The hypertrophy of the 
inferior nasal turbinate on the concave side of the NSD is called "compensatory hypertrophy" [3]. The main function of this compensatory hypertrophy is to protect the nasal airway passage from cold and dry air [4]. On most occasions, hypertrophy of the inferior nasal turbinate is reversible, however compensatory hypertrophy of the turbinate associated with NSDs is usually persistent [5] . It is also important to note that, if the hypertrophy of the turbinates is associated with NSD there is a thickness in the bony and soft tissue components of the turbinates. Conversely, only soft tissue thickening of the turbinates is observed when any other cause is associated [6]. There are only a few studies that have evaluated the association between the NSD and hypertrophy of the inferior nasal turbinate using computed tomography [7, 8]. Concha bullosa $(\mathrm{CB})$ caused by the pneumatization of the middle turbinate, may occasionally cause nasal obstruction [9]. Although there is an association between NSD and the presence of $\mathrm{CB}$, the cause-effect relationship between NSD and CB is still not very clear [9].

Although studies have investigated incidence of $\mathrm{CB}$ and HT in NSD, no studies are investigating the association or influence of these findings on NSD [9]. Our study was conducted to evaluate the association between the width of HT, CB, and NSD. Further, we also attempted to determine the influence of these variables on the type of NSD using $\mathrm{CBCT}$.

\section{Material and methods}

The ethical approval for the study was obtained from the Institutional Review Board, Gulf Medical University. CBCT scans of 100 subjects with NSDs who had earlier reported to the university teaching hospital for various dental treatments, were selected for the study based on convenience sampling.
CBCT scans of C-shaped septal deviation were evaluated by two maxillofacial radiologists. Whenever there was a disagreement a third maxillofacial radiologist was consulted. All the maxillofacial radiologists had 10 years of clinical experience.

The CBCT scans were obtained using Planmeca ProMax 3D machine. The machine functioned at $90 \mathrm{kVp}$ and $10 \mathrm{~mA}$ for image acquisition. The maxillofacial radiologists used 9 X $16 \mathrm{~cm}$ FOV.

Inclusion criteria: $\mathrm{CBCT}$ scans of subjects with anteroposterior C-shaped septal deviation, observed during the radiographic examination were included in the study. Scans of patients between 18 to 75 years of age were included in the study. Exclusion criteria: Scans with errors, artifacts, and incomplete coverage of the area of interest were excluded. CBCT scans of patients with orofacial syndromes affecting skeletal structures and patients with cleft palate were excluded.

The width of the hypertrophied turbinate (HT) and width of the non-hypertrophic turbinate bone (NHT), were measured at the anterior, middle, and posterior thirds of the inferior turbinate in coronal CBCT sections.

To achieve uniformity of calibration among the evaluators' anterior width was measured on the first image in which the entire inferior turbinate could be identified (Fig. 1a and b). The middle width was measured on the section in which the uncinate process and maxillary sinus ostium were visualized (Fig. 2). The posterior width was measured on the last image in which the entire inferior turbinate could be visualized (Fig. 3a and b) [10] .

Only Contralateral CB with a size exceeding $50 \%$ height of the middle turbinate was considered [9]. The septal deviation angle (SDA) was measured in the coronal CBCT sections using the criteria by Orhan et al. [7]. The anatomical landmarks used for measurement of the SDA are described in Fig. 4. Point A is the junction of the nasal

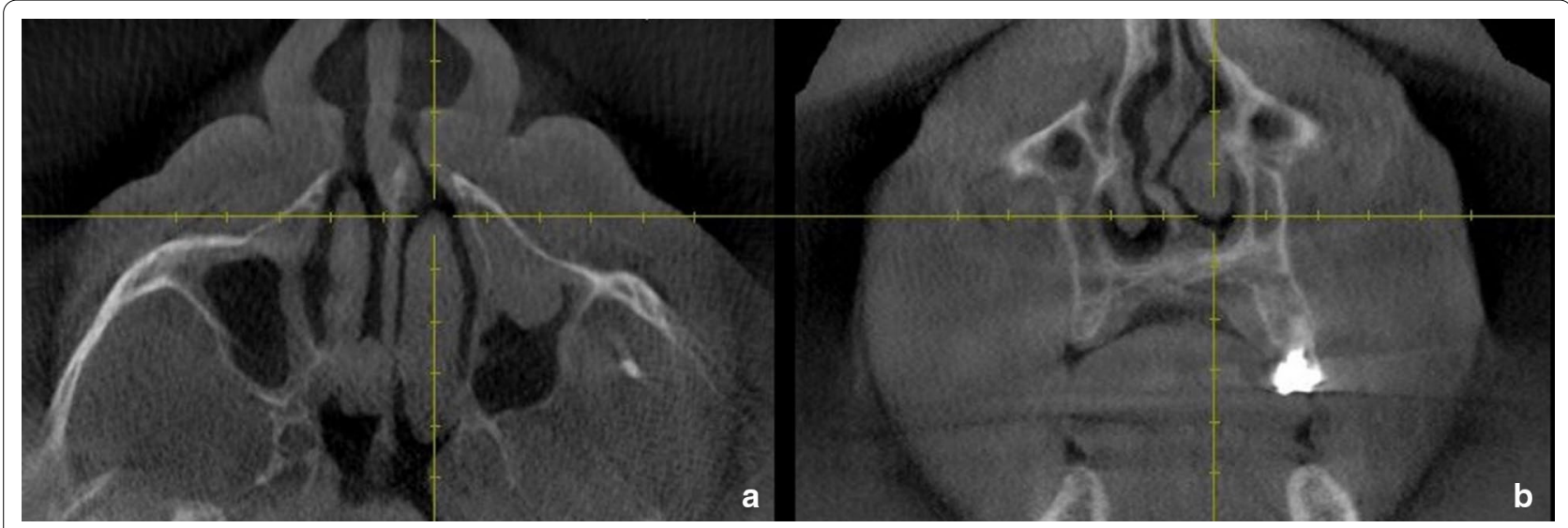

Fig. 1 Axial (a) and Coronal (b) CBCT sections showing the site at which the anterior width of the inferior turbinate was determined in the study 


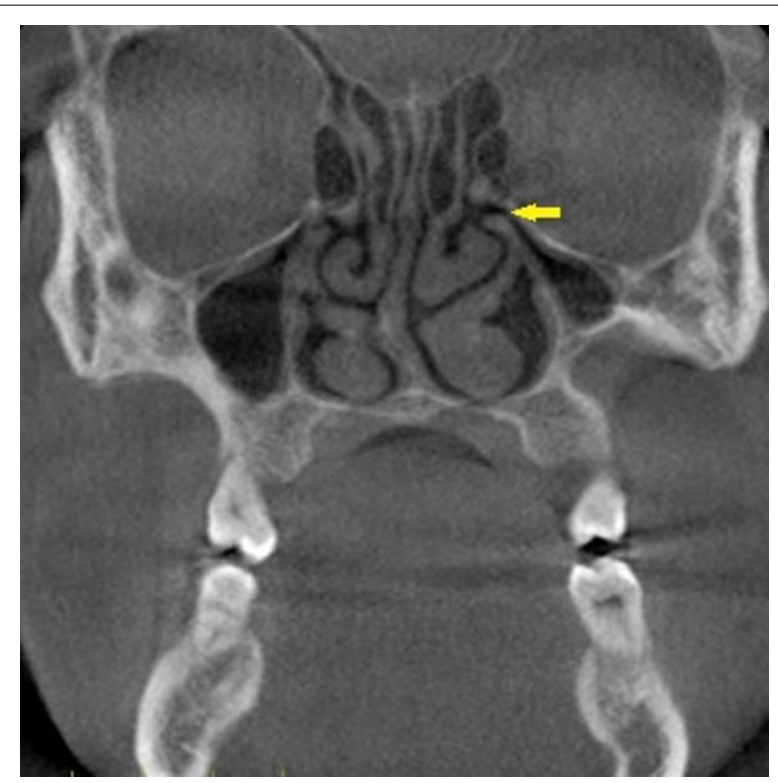

Fig. 2 Coronal CBCT section showing the site (ostium and uncinated process) at which the middle width of the turbinate was determined

septum with the floor of the nasal cavity. Point $B$ is the Crista Galli. Line $\mathrm{BC}$ is the tangent arising from point $\mathrm{B}$ and passing through the outermost part on the convexity of the deviated septum. Angle ABC is the septal deviation angle (SDA). Based on the angle of deviation, the NSDs were classified into mild (less than $\left.9^{\circ}\right)$, moderate $\left(9^{\circ}\right.$ $15^{\circ}$ ), and severe (greater than $15^{\circ}$ ). This classification was according to the criteria followed by Al-Rawi et al. [11].

The data gained after the evaluation of CBCT scans were statistically analyzed using IBM SPSS statistics (Version 22, Armonk. NY: IBM Corp).

\section{Results}

Cohens Kappa test was used to determine inter-rater reliability 0.84 . The Kappa rating rubrics suggested by Regier et al. was applied [12]. The mean SDA of the study subjects was 12.03 degrees. Mild, moderate, and severe types of NSD were observed in 38,24 , and 38 study subjects respectively. When the mean age of the subjects with different types of NSD was compared using ANOVA, no significant difference was observed $(P=0.71)$ (Table 1$)$. Further pairwise comparison using the Tukey Post Hoc test revealed, no significant difference (Table 2).

When the occurrence of the type of NSD between the genders was evaluated using Chi Square test, no significant difference was observed (Table 3).

When the anterior, middle, posterior, and mean widths of NHT and HT were compared, using the t-test, a significant difference was observed (Table 4).

When the anterior, middle, posterior and mean width of NHT were compared among the study subjects with mild, moderate and severe types of NSD there was a significant difference $(P<0.001)$ (Table 5$)$. When a pairwise comparison among the groups was carried out using the Tukey Post Hoc Test, it was observed that there was no significant difference $(p=0.27)$ in the mean width of the NHT between mild and moderate types of NSD (Table 6). However, there was a significant difference in the mean width of NHT between the mild and severe types of NSD. Similarly, there was a significant difference in the mean width of the NSD between moderate and severe types of NSD. The anterior middle and posterior width also showed changes similar to the mean width.

When the anterior, middle, posterior, and mean width of HT were compared among mild, moderate and severe types of NSD there was a significant difference $(P<0.001)$

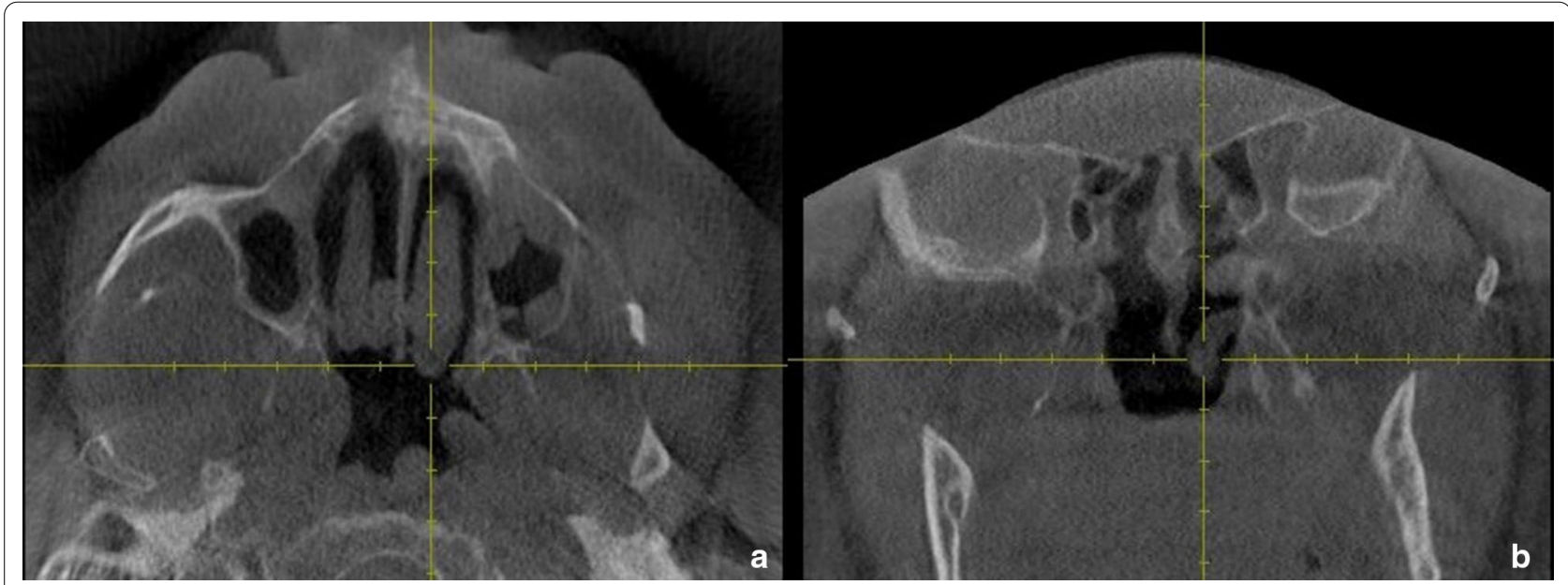

Fig. 3 Axial (a) and Coronal (b) CBCT sections showing the site at which the posterior width of the inferior turbinate was determined in the study 


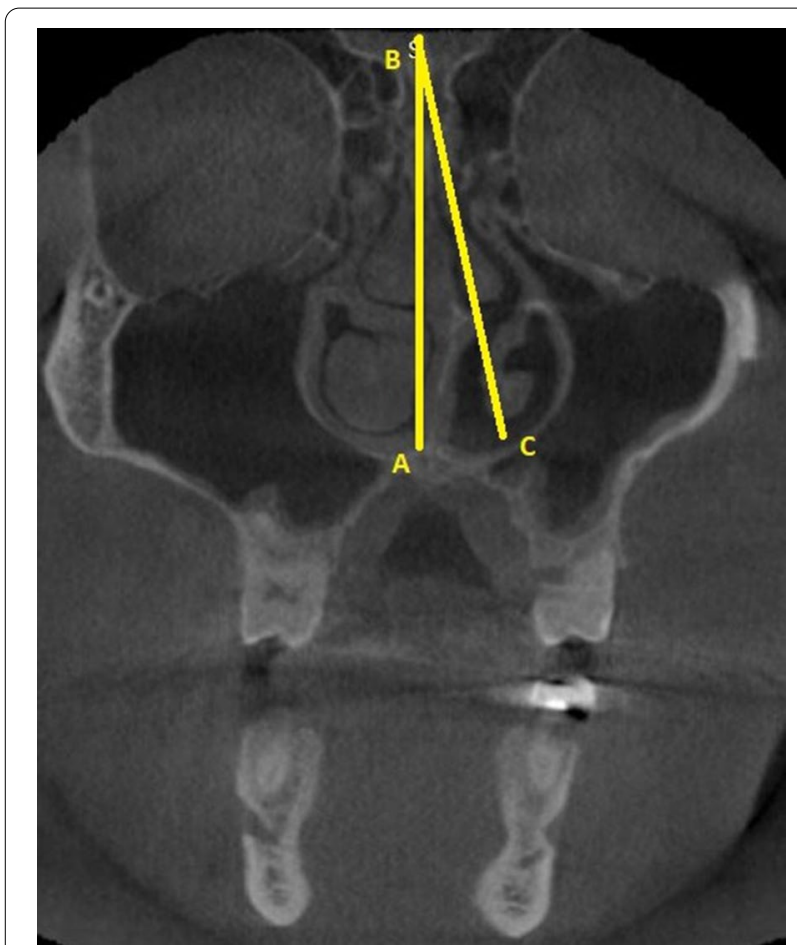

Fig. 4 Coronal CBCT section showing method used for calculating septal deviation angle SDA

(Table 7). When a pairwise comparison among the groups was carried out using the Tukey Post Hoc Test, it was observed that there was a significant difference in the anterior, middle, posterior, and mean width of the HT among mild, moderate and severe types of NSD (Table 8).
When the width of the NHT and HT were correlated with SDA there was a significant correlation $(P<0.001)$, The width of HT showed a strong correlation with SDA whereas the width of the NHT showed moderate correlation with the SDA (Table 9).

When the width of HT and NHT was compared in between study subjects with and without concha bullosa a significant difference was noted $(p<0.001)$ (Table 10). Similarly, when the SDA of study subjects with and without concha bullosa was compared a significant difference was observed $(p<0.001)$ (Table 10).

Linear regression to predict SDA based on study variables revealed that the presence of concha bullosa and middle width of the HT are significant predictors of SDA. The presence of concha corresponds to a 2.10 unit change in the SDA $(\mathrm{R} 2=0.19)$ and for every unit increase in middle width of the $\mathrm{HT}$, there is a 2.28 unit change in SDA $(\mathrm{R} 2=0.42)$. The presence of $\mathrm{CB}$ was associated with a significant increase in the width of HT and NHT. (Table 11).

Ordinal logistic regression revealed that width of the middle HT $(p=0.01)$ and presence of concha $(p=0.04)$ had a significant influence on the type of NSD (Table 12).

\section{Discussion}

Nasal turbinate hypertrophy can occur due to congenital or acquired causes. Acquired causes can be secondary to conditions like allergic rhinitis, dust allergy, pregnancy, hyperthyroidism, and rebound nasal congestion due to extended use of topical decongestants [13]. Although turbinate hypertrophy is transient, the presence of NSD makes the hypertrophy persistent [14]. NSD is a common problem in the middle

Table 1 Comparison of mean age of study subjects with different types of NSD

\begin{tabular}{|c|c|c|c|c|c|c|c|c|}
\hline & \multirow[t]{2}{*}{ Group } & \multirow[t]{2}{*}{$\mathbf{N}$} & \multirow[t]{2}{*}{ Mean } & \multirow[t]{2}{*}{ SD } & \multirow[t]{2}{*}{ Min } & \multirow[t]{2}{*}{ Max } & \multicolumn{2}{|c|}{ ANOVA } \\
\hline & & & & & & & $F$ & $p$-value \\
\hline \multirow[t]{3}{*}{ Age } & Mild & 38 & 40.29 & 12.92 & 22.00 & 67.00 & 0.35 & 0.71 (NS) \\
\hline & Moderate & 24 & 43.17 & 14.64 & 18.00 & 70.00 & & \\
\hline & Severe & 38 & 41.74 & 12.86 & 22.00 & 75.00 & & \\
\hline
\end{tabular}

${ }^{*} p<0.05$ Statistically Significant, $p>0.05$ Non Significant

Table 2 Pairwise comparison of the mean age of study subjects between different types of NSD

\begin{tabular}{|c|c|c|c|c|c|c|c|}
\hline \multirow[t]{2}{*}{ Dependent Variable } & \multirow[t]{2}{*}{ (I) Type } & \multirow[t]{2}{*}{ (J) Type } & \multirow{2}{*}{$\begin{array}{l}\text { Mean } \\
\text { Difference (I-J) }\end{array}$} & \multirow[t]{2}{*}{ Std. Error } & \multirow[t]{2}{*}{$p$-value } & \multicolumn{2}{|c|}{ 95\% Confidence Interval } \\
\hline & & & & & & Lower Bound & Upper Bound \\
\hline \multirow[t]{3}{*}{ Age } & Mild & Moderate & -2.88 & 3.47 & 0.69 (NS) & -11.15 & 5.39 \\
\hline & & Severe & -1.45 & 3.06 & 0.88 (NS) & -8.72 & 5.83 \\
\hline & Moderate & Severe & 1.43 & 3.47 & 0.91 (NS) & -6.84 & 9.70 \\
\hline
\end{tabular}


Table 3 Comparison of gender and the types of NSD

\begin{tabular}{|c|c|c|c|c|c|c|c|}
\hline & & \multicolumn{3}{|l|}{ Type } & \multirow[t]{2}{*}{ Total } & \multicolumn{2}{|l|}{ Chi-Square test } \\
\hline & & Mild & Moderate & severe & & Chi-Square value & $p$-value \\
\hline \multirow[t]{4}{*}{ Gender } & Male & 20 & 14 & 24 & 58 & 0.87 & 0.65 (NS) \\
\hline & & $52.6 \%$ & $58.3 \%$ & $63.2 \%$ & $58.0 \%$ & & \\
\hline & Female & 18 & 10 & 14 & 42 & & \\
\hline & & $47.4 \%$ & $41.7 \%$ & $36.8 \%$ & $42.0 \%$ & & \\
\hline
\end{tabular}

${ }^{*} p<0.05$ Statistically Significant, $p>0.05$ Non Significant, NS

Table 4 Comparison of the anterior, middle and posterior widths between NHT and HT

\begin{tabular}{|c|c|c|c|c|c|c|c|c|c|c|}
\hline & \multirow[t]{2}{*}{ Width } & \multirow[t]{2}{*}{$\mathrm{N}$} & \multirow[t]{2}{*}{ Mean } & \multirow[t]{2}{*}{ SD } & \multirow[t]{2}{*}{ Mean Difference } & \multicolumn{2}{|c|}{$\begin{array}{l}95 \% \text { Confidence } \\
\text { Interval of the } \\
\text { Difference }\end{array}$} & \multirow[t]{2}{*}{$t$} & \multirow[t]{2}{*}{ df } & \multirow[t]{2}{*}{$p$-value } \\
\hline & & & & & & Lower & Upper & & & \\
\hline \multirow[t]{2}{*}{ Anterior Width } & NHT & 100 & 7.78 & 0.99 & -4.18 & -4.87 & -3.50 & -12.15 & 99 & $<0.001^{*}$ \\
\hline & $\mathrm{HT}$ & 100 & 11.97 & 3.92 & & & & & & \\
\hline \multirow[t]{2}{*}{ Middle Width } & NHT & 100 & 8.04 & 1.18 & -4.13 & -4.75 & -3.50 & -13.02 & 99 & $<0.001^{*}$ \\
\hline & HT & 100 & 12.17 & 3.89 & & & & & & \\
\hline \multirow[t]{2}{*}{ Posterior Width } & NHT & 100 & 6.08 & 0.91 & -1.38 & -1.81 & -0.94 & -6.28 & 99 & $<0.001^{*}$ \\
\hline & $\mathrm{HT}$ & 100 & 7.46 & 2.57 & & & & & & \\
\hline \multirow[t]{2}{*}{ Mean Width } & NHT & 100 & 7.30 & 0.91 & -3.23 & -3.79 & -2.67 & -11.46 & 99 & $<0.001^{*}$ \\
\hline & $\mathrm{HT}$ & 100 & 10.53 & 3.36 & & & & & & \\
\hline
\end{tabular}

${ }^{*} p<0.05$ Statistically Significant, $p>0.05$ Non Significant, NS

Table 5 Comparison of the width of NHT width among the types of NSD

\begin{tabular}{|c|c|c|c|c|c|c|c|c|}
\hline \multirow[t]{2}{*}{ NHT } & \multirow[t]{2}{*}{ Type of NSD } & \multirow[t]{2}{*}{$\mathbf{N}$} & \multirow[t]{2}{*}{ Mean } & \multirow[t]{2}{*}{ SD } & \multirow[t]{2}{*}{ Min } & \multirow[t]{2}{*}{ Max } & \multicolumn{2}{|c|}{ ANOVA } \\
\hline & & & & & & & $\mathbf{F}$ & $p$-value \\
\hline \multirow[t]{3}{*}{ Anterior Width } & Mild & 38 & 7.18 & 0.72 & 5.23 & 8.89 & 27.88 & $<0.001^{*}$ \\
\hline & Moderate & 24 & 7.58 & 0.82 & 6.06 & 9.45 & & \\
\hline & Severe & 38 & 8.52 & 0.84 & 6.67 & 10.99 & & \\
\hline \multirow[t]{3}{*}{ Middle Width } & Mild & 38 & 7.25 & 0.67 & 5.65 & 8.45 & 37.87 & $<0.001^{*}$ \\
\hline & Moderate & 24 & 7.77 & 0.67 & 6.43 & 8.67 & & \\
\hline & Severe & 38 & 9.00 & 1.17 & 7.45 & 11.33 & & \\
\hline \multirow[t]{3}{*}{ Posterior Width } & Mild & 38 & 5.80 & 0.76 & 4.01 & 7.88 & 12.02 & $<0.001^{*}$ \\
\hline & Moderate & 24 & 5.72 & 0.68 & 4.88 & 7.56 & & \\
\hline & Severe & 38 & 6.60 & 0.94 & 4.67 & 8.45 & & \\
\hline \multirow[t]{3}{*}{ Mean Width } & Mild & 38 & 6.74 & 0.63 & 5.33 & 8.08 & 35.20 & $<0.001^{*}$ \\
\hline & Moderate & 24 & 7.03 & 0.58 & 6.11 & 8.33 & & \\
\hline & Severe & 38 & 8.04 & 0.82 & 6.59 & 9.48 & & \\
\hline
\end{tabular}

${ }^{*} p<0.05$ Statistically Significant, $p>0.05$ Non Significant, NS

eastern population [11]. Computed Tomography (CT) is currently being used to study NSD and associated sino-nasal conditions [15]. Since inflammatory sinus diseases are often recurring and require repetitive imaging $\mathrm{CBCT}$ could be a suitable alternative to
CT since the former is associated with a significantly lower dose of radiation [16]. However, a recent survey revealed that the knowledge regarding applications and advantages of CBCT is very limited among otolaryngologists [17]. This study was conducted to analyze 
Table 6 Pairwise comparison of the width of NHT between individual types of NSD

\begin{tabular}{|c|c|c|c|c|c|c|c|}
\hline \multirow[t]{2}{*}{ TNHT } & \multirow[t]{2}{*}{ (I) Type } & \multirow[t]{2}{*}{ (J) Type } & \multirow{2}{*}{$\begin{array}{l}\text { Mean } \\
\text { Difference (I-J) }\end{array}$} & \multirow[t]{2}{*}{ Std. Error } & \multirow[t]{2}{*}{$p$-value } & \multicolumn{2}{|c|}{ 95\% Confidence Interval } \\
\hline & & & & & & Lower Bound & Upper Bound \\
\hline \multirow[t]{3}{*}{ Anterior Width } & Mild & Moderate & -0.40 & 0.21 & 0.13 (NS) & -0.90 & 0.09 \\
\hline & & Severe & -1.34 & 0.18 & $<0.001^{*}$ & -1.77 & -0.90 \\
\hline & Moderate & Severe & -0.93 & 0.21 & $<0.001^{*}$ & -1.43 & -0.44 \\
\hline \multirow[t]{3}{*}{ Middle Width } & Mild & Moderate & -0.52 & 0.23 & 0.07 (NS) & -1.07 & 0.03 \\
\hline & & Severe & -1.75 & 0.20 & $<0.001^{*}$ & -2.24 & -1.26 \\
\hline & Moderate & Severe & -1.23 & 0.23 & $<0.001^{*}$ & -1.78 & -0.67 \\
\hline \multirow[t]{3}{*}{ Posterior Width } & Mild & Moderate & 0.08 & 0.21 & 0.93 (NS) & -0.43 & 0.59 \\
\hline & & Severe & -0.80 & 0.19 & $<0.001^{*}$ & -1.25 & -0.35 \\
\hline & Moderate & Severe & -0.87 & 0.21 & $<0.001^{*}$ & -1.38 & -0.36 \\
\hline \multirow[t]{3}{*}{ Mean Width } & Mild & Moderate & -0.28 & 0.18 & 0.27 (NS) & -0.71 & 0.15 \\
\hline & & Severe & -1.29 & 0.16 & $<0.001^{*}$ & -1.67 & -0.91 \\
\hline & Moderate & Severe & -1.01 & 0.18 & $<0.001^{*}$ & -1.44 & -0.58 \\
\hline
\end{tabular}

Tukey Post Hoc Test ${ }^{*} p<0.05$ Statistically Significant, $p>0.05$ Non Significant, NS

Table 7 Comparison of the width of HT among the types of NSD

\begin{tabular}{|c|c|c|c|c|c|c|c|c|}
\hline \multirow[t]{2}{*}{ HT } & \multirow[t]{2}{*}{ Type } & \multirow[t]{2}{*}{$\mathrm{N}$} & \multirow[t]{2}{*}{ Mean } & \multirow[t]{2}{*}{ SD } & \multirow[t]{2}{*}{ Min } & \multirow[t]{2}{*}{ Max } & \multicolumn{2}{|c|}{ ANOVA } \\
\hline & & & & & & & $F$ & $p$-value \\
\hline \multirow[t]{3}{*}{ Anterior Width } & Mild & 38 & 9.42 & 2.18 & 5.34 & 14.78 & 28.16 & $<0.001^{*}$ \\
\hline & Moderate & 24 & 11.50 & 3.22 & 7.08 & 18.11 & & \\
\hline & Severe & 38 & 14.81 & 3.85 & 8.08 & 20.11 & & \\
\hline \multirow[t]{3}{*}{ Middle Width } & Mild & 38 & 9.64 & 2.00 & 6.74 & 14.45 & 29.83 & $<0.001^{*}$ \\
\hline & Moderate & 24 & 11.56 & 3.23 & 8.11 & 18.56 & & \\
\hline & Severe & 38 & 15.07 & 3.83 & 9.04 & 20.28 & & \\
\hline \multirow[t]{3}{*}{ Posterior Width } & Mild & 38 & 6.27 & 1.19 & 4.01 & 9.76 & 14.71 & $<0.001^{*}$ \\
\hline & Moderate & 24 & 6.89 & 2.44 & 4.88 & 12.34 & & \\
\hline & Severe & 38 & 9.00 & 2.90 & 5.11 & 15.09 & & \\
\hline \multirow[t]{3}{*}{ Mean Width } & Mild & 38 & 8.45 & 1.65 & 6.26 & 12.37 & 26.77 & $<0.001^{*}$ \\
\hline & Moderate & 24 & 9.98 & 2.85 & 6.98 & 16.34 & & \\
\hline & Severe & 38 & 12.96 & 3.41 & 8.04 & 17.33 & & \\
\hline
\end{tabular}

${ }^{*} p<0.05$ Statistically Significant, $p>0.05$ Non Significant, NS

NSD, $\mathrm{CB}$, and associated changes in the inferior nasal turbinate using $\mathrm{CBCT}$.

In the present study, the mean SDA of the patients with NSD was 12.03 degrees. Similar SDA values were reported by Demir D et al., Orhan I et al., Keles B et al. and Serifoglu I et al. in their studies conducted on the Turkish population $[5,7,18,19]$. A study conducted in Serbian population also reported a similar mean SDA value, as reported in the present study [20]. Another study conducted using CT on the Iraqi population also reported mean SDA values as reported in the present study [21]. However, in a study by conducted by Codari $\mathrm{M}$ et al. in the Italian population, the mean SDA was
17.3 degrees [22]. Another CT-based study conducted in the Iranian population also reported of lower mean SDA values compared to the present study [23].

In the present study, NSD was classified as mild, moderate, and severe based on SDA. In a recent study, few authors have categorized SDA from Type I to Type IV and reported that Type II SDA (5-10 degrees) was the most common in occurrence [24]. Although a majority of the studies have reported mean SDA values similar to that of our present study, there are some studies that have reported different mean SDA values. This difference in mean SDA values among studies could be attributed to racial variations in the study 
Table 8 Pairwise comparison of the width HT between the individual types of NSD

\begin{tabular}{|c|c|c|c|c|c|c|c|}
\hline \multirow[t]{2}{*}{ HT } & \multirow[t]{2}{*}{ (I) Type } & \multirow[t]{2}{*}{ (J) Type } & \multirow{2}{*}{$\begin{array}{l}\text { Mean } \\
\text { Difference (I-J) }\end{array}$} & \multirow[t]{2}{*}{ Std. Error } & \multirow[t]{2}{*}{$p$-value } & \multicolumn{2}{|c|}{ 95\% Confidence Interval } \\
\hline & & & & & & Lower Bound & Upper Bound \\
\hline \multirow[t]{3}{*}{ Anterior Width } & Mild & Moderate & -2.08 & 0.82 & $0.03^{*}$ & -4.04 & -0.13 \\
\hline & & Severe & -5.39 & 0.72 & $<0.001^{*}$ & -7.11 & -3.67 \\
\hline & Moderate & Severe & -3.30 & 0.82 & $<0.001^{*}$ & -5.26 & -1.35 \\
\hline \multirow[t]{3}{*}{ Middle Width } & Mild & Moderate & -1.91 & 0.81 & $0.04^{*}$ & -4.83 & -0.11 \\
\hline & & Severe & -5.43 & 0.71 & $<0.001^{*}$ & -7.12 & -3.74 \\
\hline & Moderate & Severe & -3.52 & 0.81 & $<0.001^{*}$ & -5.44 & -1.59 \\
\hline \multirow[t]{3}{*}{ Posterior Width } & Mild & Moderate & -0.62 & 0.59 & $0.01^{*}$ & -2.03 & 0.79 \\
\hline & & Severe & -2.73 & 0.52 & $<0.001^{*}$ & -3.97 & -1.49 \\
\hline & Moderate & Severe & -2.11 & 0.59 & $0.002^{*}$ & -3.52 & -0.70 \\
\hline \multirow[t]{3}{*}{ Mean Width } & Mild & Moderate & -1.54 & 0.71 & $0.04^{*}$ & -4.23 & 0.15 \\
\hline & & Severe & -4.52 & 0.62 & $<0.001^{*}$ & -6.00 & -3.03 \\
\hline & Moderate & Severe & -2.98 & 0.71 & $<0.001^{*}$ & -4.67 & -1.29 \\
\hline
\end{tabular}

Tukey Post Hoc Test ${ }^{*} p<0.05$ Statistically Significant, $p>0.05$ Non Significant, NS

Table 9 Correlation between the width of NHT and HT with SDA

\begin{tabular}{llll}
\hline & Region & SDA & \\
\cline { 3 - 4 } & & $\begin{array}{l}\text { Correlation } \\
\text { Coefficient }\end{array}$ & $\boldsymbol{p}$-value \\
\hline HT & Anterior Width & 0.68 & $<0.001^{*}$ \\
& Middle Width & 0.70 & $<0.001^{*}$ \\
Posterior Width & 0.76 & $<0.001^{*}$ \\
NHT & Mean Width & 0.71 & $<0.001^{*}$ \\
& Anterior Width & 0.52 & $<0.001^{*}$ \\
& Middle Width & 0.57 & $<0.001^{*}$ \\
& Posterior Width & 0.56 & $<0.001^{*}$ \\
& Mean Width & 0.55 & $<0.001^{*}$ \\
\hline
\end{tabular}

${ }^{*} p<0.05$ Statistically Significant, $p>0.05$ Non Significant, NS

population and the measurement techniques used in different studies [20].

In the present study, the occurrence of the types of NSD was not correlated to age of the study subjects. Similar results were presented by Goergen MJ et al. and Yonis MA et al. in the American and Egyptian populations [25, 26]. Besides the occurrence of the types of NSD did not show any difference between the genders of the patients. This finding was consistent with the study results of Serifoglu I et al., Altunay ZO et al. Shobeiri et al. [19, 27, 28]. On contrary a recent Turkish study reported a significantly high mean SDA among men compared to women [29].

Our study results are highly consistent with the literature evidence that there is no notable difference in the mean SDA concerning the age and sex of study subjects. In the current study the mean width of NHT and the mean width HT in patients with NSD was $7.27 \pm 0.67 \mathrm{~m}$ and $10.46 \pm 2.63 \mathrm{~mm}$ respectively. Similar measurements were presented in many CT studies from Egypt and Iraq [30-33].

A significant difference was noted between the anterior, middle, and posterior widths of HT and NHT in our study. A similar difference was published by many authors in patients with NSD $[6,7,34,35]$. However, the current study used CBCT while all the previous studies were carried out using CT.

Various reference points were used by different authors for the measurement of turbinate width. Orhan et al. measured the widest part of the turbinate while Kang JW et al. measured it at the front part of the vertical portion of the uncinated process and Tombilson $\mathrm{CM}$ et al. used ostium as a standard point for measurement [7, 35, 36].

While most of the studies used a single reference point for width measurement Egeli et al. used three standard reference points [6]. In the present study turbinate width was measured at 3 standard points. Measurement of width at multiple standard points is important because the turbinates show significant changes in width in different areas [8].

It was initially assumed that the compensatory hypertrophy of the nasal turbinates was purely mucosal [3]. Later radiographic and histopathological studies revealed that the hypertrophy of the bony component of the turbinate along with the mucosal component [36].

Further studies revealed that the bony component of the inferior turbinate becomes thicker, spongier, and tends to arch medially into the nasal airway [3]. The mucosal component undergoes hypertrophy by building up a rich network of venous sinusoids and thereby acquire an exaggerated capacity to expand [3]. 
Table 10 Comparison of the width of NHT, HT and SDA according to the presence of concha bullosa

\begin{tabular}{|c|c|c|c|c|c|c|c|c|c|c|c|}
\hline & & \multirow[t]{2}{*}{ Concha bullosa } & \multirow[t]{2}{*}{$\mathrm{N}$} & \multirow[t]{2}{*}{ Mean } & \multirow[t]{2}{*}{ SD } & \multirow[t]{2}{*}{ Mean Difference } & \multicolumn{2}{|c|}{$\begin{array}{l}95 \% \text { Confidence } \\
\text { Interval of the } \\
\text { Difference }\end{array}$} & \multirow[t]{2}{*}{$t$} & \multirow[t]{2}{*}{ df } & \multirow[t]{2}{*}{$p$-value } \\
\hline & & & & & & & Lower & Upper & & & \\
\hline \multirow[t]{8}{*}{ NHT } & Anterior Width & Absent & 63 & 7.53 & 0.87 & -0.68 & -1.06 & -0.29 & -3.49 & 98 & $0.04^{*}$ \\
\hline & & Present & 37 & 8.21 & 1.04 & & & & & & \\
\hline & Middle Width & Absent & 63 & 7.72 & 0.98 & -0.87 & -1.33 & -0.42 & -3.81 & 98 & $0.02^{*}$ \\
\hline & & Present & 37 & 8.59 & 1.30 & & & & & & \\
\hline & Posterior Width & Absent & 63 & 5.93 & 0.84 & -0.42 & -0.78 & -0.05 & -2.26 & 98 & $0.03^{*}$ \\
\hline & & Present & 37 & 6.35 & 0.97 & & & & & & \\
\hline & Mean Width & Absent & 63 & 7.06 & 0.79 & -0.65 & -1.01 & -0.30 & -3.71 & 98 & $0.04^{*}$ \\
\hline & & Present & 37 & 7.72 & 0.96 & & & & & & \\
\hline \multirow[t]{10}{*}{ HT } & Anterior Width & Absent & 63 & 10.85 & 3.21 & -3.02 & -4.52 & -1.52 & -3.99 & 98 & $<0.001^{*}$ \\
\hline & & Present & 37 & 13.87 & 4.32 & & & & & & \\
\hline & Middle Width & Absent & 63 & 11.06 & 3.17 & -3.00 & -4.49 & -1.50 & -3.99 & 98 & $<0.001^{*}$ \\
\hline & & Present & 37 & 14.05 & 4.30 & & & & & & \\
\hline & Posterior Width & Absent & 63 & 6.91 & 2.09 & -1.48 & -2.50 & -0.46 & -2.89 & 98 & $0.005^{*}$ \\
\hline & & Present & 37 & 8.39 & 3.03 & & & & & & \\
\hline & Mean Width & Absent & 63 & 9.61 & 2.74 & -2.50 & -3.79 & -1.21 & -3.84 & 98 & $<0.001^{*}$ \\
\hline & & Present & 37 & 12.11 & 3.75 & & & & & & \\
\hline & SDA & Absent & 63 & 10.13 & 5.08 & -4.96 & -6.92 & -3.00 & -5.03 & 98 & $<0.001^{*}$ \\
\hline & & Present & 37 & 15.09 & 4.15 & & & & & & \\
\hline
\end{tabular}

${ }^{*} p<0.05$ Statistically Significant, $p>0.05$ Non Significant, NS

Table 11 Linear regression to predict SDA based on study variables

\begin{tabular}{|c|c|c|c|c|c|c|c|}
\hline & \multicolumn{2}{|c|}{ Unstandardized Coefficients } & \multirow{2}{*}{$\begin{array}{l}\text { Standardized } \\
\text { Coefficients } \\
\text { Beta }\end{array}$} & \multirow[t]{2}{*}{$\mathbf{t}$} & \multirow[t]{2}{*}{$p$-value } & \multicolumn{2}{|c|}{$95.0 \%$ Confidence Interval for B } \\
\hline & B & Std. Error & & & & Lower Bound & Upper Bound \\
\hline (Constant) & -11.93 & 2.92 & & -4.09 & $<0.001^{*}$ & -17.73 & -6.14 \\
\hline Concha bullosa & 2.10 & 0.79 & 0.19 & 2.65 & $0.01^{*}$ & 0.52 & 3.67 \\
\hline HT middle width & 2.28 & 0.44 & 0.42 & 5.16 & $<0.001^{*}$ & 1.40 & 3.16 \\
\hline
\end{tabular}

Dependent Variable: SDA

$F(3,99)=43.94, P<0.001, R^{2}=0.76,{ }^{*} p<0.05$ Statistically Significant, $p>0.05$ Non Significant, NS

Researchers have also detected histopathological differences in the NSD induced compensatory and allergic hypertrophy of the nasal turbinate [37]. Compensatory hypertrophy of the inferior turbinate is usually associated with increased venous sinusoids, fibrosis around the blood vessels and normal glands, whereas allergyinduced hypertrophy comprises glandular hyperplasia and significant edema $[37,38]$.

The submucosal blood vessels and glands of the inferior turbinates are under autonomic control. They a vital role in maintaining the local homeostasis by controlling the nasal secretions, nasal patency, and humidification of air in the nasal cavity [39]. In compensatory hypertrophy, this delicate homeostasis is altered [40].
In the present study, there was a significant difference in the anterior, middle, posterior and mean width of HT among mild, moderate, and severe types of NSD. Similar findings were observed in the CT-based studies by Orhan et al., Tombilson et al. and Egeli et al. [6, 7, 34]. However, Demir et al. report no significant difference in the width of the turbinates with alteration in NSD. [1]. This finding could be attributed to the fact that Demir et al. evaluated middle turbinate hypertrophy whereas inferior turbinate hypertrophy was evaluated in the present study.

Two theories are proposed to describe the correlation between turbinate hypertrophy and NSD [6]. The first and widely accepted theory states that the hypertrophy of the contralateral inferior turbinate occurs as a 


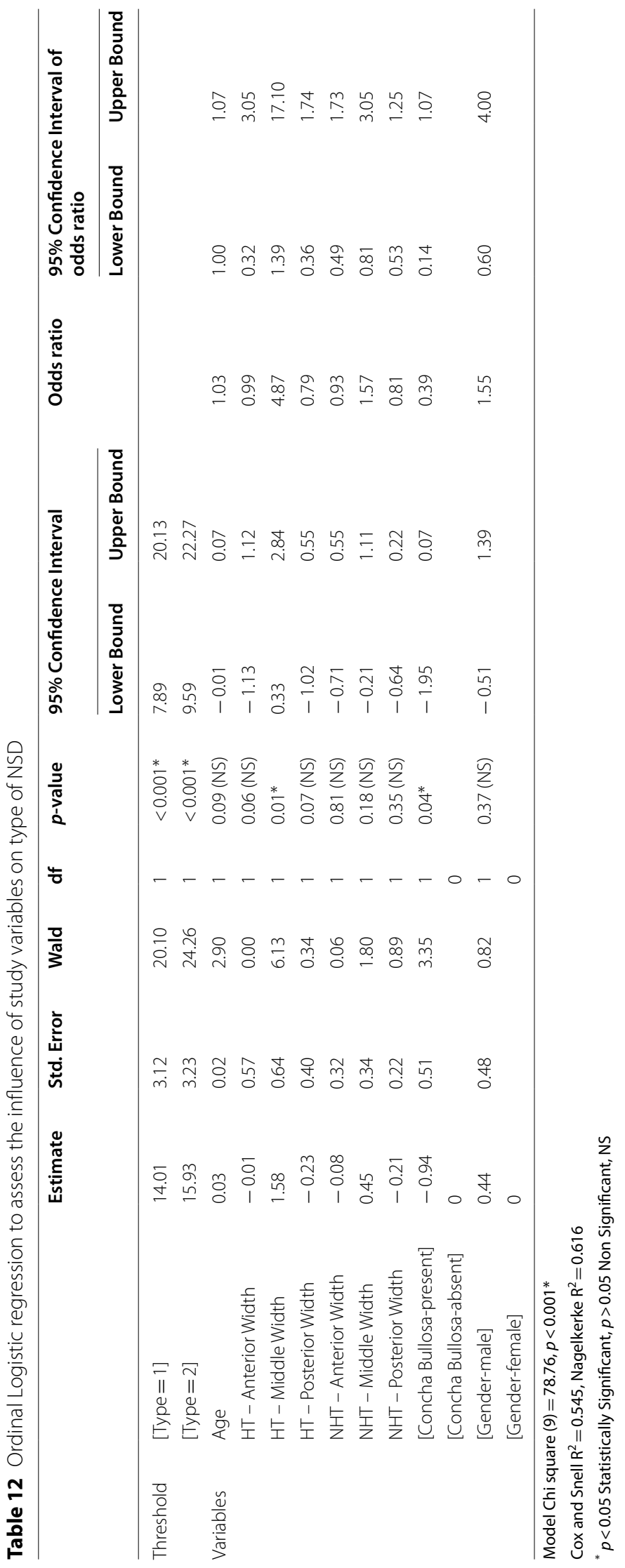


compensatory reaction to NSD. The second theory states that the unilateral growth of the nasal turbinate results from genetic causes or early life trauma which is likely to exert pressure on the growing nasal septum throughout childhood and puberty. This constant pressure leads to the deviation of the nasal septum to the contralateral side. The theory considerably substantiates the fact that bony enlargement significantly contributes to the measured thickness of the turbinate in compensatory hypertrophy [6].

In the present study, there was a significant increase in width of HT, NHT, and the degree of SDA when CB was present. Similar findings were reported by Tombilson et al. and Stallman et al. [9, 35]. The literature suggests a strong association between NSD and CB however, their relationship is not clear in terms of cause-effect relationship [35]. The theory of "e vacuo hypothesis" states that CB only fills the space created by NSD [39].

Studies have also suggested that the septum is typically pushed away from the $\mathrm{CB}$ when present unilaterally and pushed away from the dominant concha bullosa when present bilaterally when bilateral $[9,38]$.

In the present study, ordinal logistic regression revealed that width of the middle $\mathrm{HT}$ and presence of concha $(p=0.04)$ had a significant influence on the type of NSD which is similar to findings in the CT-based study by Tombilson CM et al., that showed that CB had a significant influence on the degree of NSD [35]. In our study, the middle width of the HT had a significant influence on the NSD. Mrig et al. found that the medial mucosa undergoes maximal hypertrophy compared to the rest of the areas [8]. This might be the probable reason for the significant association between the middle width of HT and NSD observed in our study.

NSD associated compensatory hypertrophy leads to the chronic nasal obstruction which can significantly affect the quality of life, productivity, and finances [40]. When drug therapy is unsuccessful in reducing compensatory hypertrophy, a surgical line of management is often recommended [41, 42]. A recent expert consensus meets states that inferior turbinoplasty is an effective adjunctive procedure to septoplasty in the presence of hypertrophic inferior turbinates $[43,44]$. The diagnosis, treatment and follow-up of compensatory hypertrophy associated with NSD would require multiple imaging studies. Although $\mathrm{CT}$ is used for imaging for compensatory hypertrophy associated with NSD, CBCT could be used a suitable alternative with a relatively lower dose of radiation [45].

\section{Conclusion}

From the results of the study we can conclude that the middle width of the inferior hypertrophic turbinate and the presence of concha influence the degree of NSD. The present study results also recommend the use of $\mathrm{CBCT}$ as a substitutive low radiation dose imaging modality for evaluation of NSD, CB, and associated inferior turbinate hypertrophy.

\section{Abbreviations \\ CT: Computed tomography; CBCT: Cone beam computed tomography; CB: Concha bullosa; NSD: Nasal septal deviation; SDA: Septal deviation angle; HT: Hypertrophied turbinate; NHT: Non-Hypertrophied turbinate.}

\section{Authors' contributions}

Dr. Shishir Ram Shetty: Concept, data collection, manuscript writing. Dr. Saad Wahby Al Bayatti: Manuscript writing. Prof. Natheer Hashim Al-Rawi: Manuscript writing. Prof. Hesham Marei: Data collection. Dr. Sesha Reddy: Data collection. Prof. Hossam Abdelatty Abdelmagyd: Data collection. Dr. Sangeetha Narasimhan: Manuscript writing. Prof. Sausan Al Kawas: Manuscript writing. Dr. Asok Mathew: Manuscript writing. All authors read and approved the final manuscript.

\section{Availability of data and materials}

The corresponding can be contacted for raw data. The data is also available at figshare; https://doi.org/10.6084/m9.figshare.14413730

\section{Declarations}

Ethics approval and informed consent to participate

All methods were carried out in accordance with relevant guidelines and regulations. All experimental protocols were approved by a named institutional ethical committee obtained Ref. no. INT/COD/FR/006-2020 (Institutional review board, Gulf Medical University). Informed consent was obtained from all subjects, if subjects are under 18, consent was obtained from a parent and/ or legal guardian.

\section{Competing interests}

The authors declare no competing interests.

\section{Author details}

${ }^{1}$ College of Dental Medicine, University of Sharjah, Sharjah, United Arab Emirates. ${ }^{2}$ College of Dentistry, Gulf Medical University, Ajman, United Arab Emirates. ${ }^{3}$ University of Science and Technology of Fujairah, Fujairah, United Arab Emirates. ${ }^{4}$ Department of Oral and Craniofacial Health Sciences, College of Dental Medicine, University of Sharjah, Sharjah, United Arab Emirates.

Received: 28 February 2021 Accepted: 19 April 2021

Published online: 24 April 2021

\section{References}

1. Demir D, Asil K, Güven M, Kayabaşoğlu G, Yılmaz MS. Assessment of the correlation between nasal septal deviation and compensatory hypertrophy of the middle turbinate. Eur Arch Otorhinolaryngol. 2015;272(10):2847-51.

2. Gray LP. Deviated nasal septum. Incidence and etiology. Ann Otol Rhinol Laryngol Suppl. 1978;87(Suppl 50):3-20.

3. Berger G, Hammel I, Berger R, Avraham S, Ophir D. Histopathology of the inferior turbinate with compensatory hypertrophy in patients with deviated nasal septum. Laryngoscope. 2000;110(12):2100-5.

4. Grymer LF, Illum P, Hilberg O. Septoplasty and compensatory inferior turbinate hypertrophy: a randomized study evaluated by acoustic rhinometry. J Laryngol Otol. 1993;107(5):413-7.

5. Demir U, Durgut O, Saraydaroglu G, Onart S, Ocakoglu G. Efficacy of radiofrequency turbinate reduction: evaluation by computed tomography and acoustic rhinometry. J Otolaryngol Head Neck Surg. 2012;41(4):274-81. 
6. Egeli E, Demirci L, Yazýcý B, Harputluoglu U. Evaluation of the inferior turbinate in patients with deviated nasal septum by using computed tomography. Laryngoscope. 2004;114(1):113-7.

7. Orhan I, Aydın S, Ormeci T, YIImaz F. A radiological analysis of inferior turbinate in patients with deviated nasal septum by using computed tomography. Am J Rhinol Allergy. 2014;28(1):e68-72.

8. Mrig S, Agarwal AK, Passey JC. Preoperative computed tomographic evaluation of inferior nasal concha hypertrophy and its role in deciding surgical treatment modality in patients with deviated nasal septum. Int J Morphol. 2009;27(2):503-6.

9. Stallman JS, Lobo JN, Som PM. The incidence of concha bullosa and its relationship to nasal septal deviation and paranasal sinus disease. AJNR Am J Neuroradiol. 2004:25:1613-8.

10. Ural A, Kanmaz A, Inançli HM, Imamoğlu M. Association of inferior turbinate enlargement, concha bullosa and nasal valve collapse with the convexity of septal deviation. Acta Otolaryngol. 2010;130(2):271-4.

11. Al-Rawi NH, Uthman AT, Abdulhameed E, Al Nuaimi AS, Seraj Z. Concha bullosa, nasal septal deviation, and their impacts on maxillary sinus volume among Emirati people: a cone-beam computed tomography study. Imaging Sci Dent. 2019:49(1):45-51.

12. Regier DA, Narrow WE, Clarke DE, Kraemer HC, Kuramoto JS, Kuhl EA, Kupfer DJ. DSM-5 field trials in the United States and Canada, part II: test-retest reliability of selected categorical diagnoses. Am J Psychiatry. 2013:170:59-70.

13. Courtiss EH, Goldwyn RM, O'Brien JJ. Resection of obstructing inferior nasal turbinates. Plast Reconstr Surg. 1978;62:249-57.

14. Berger G, Hammel I, Berger R, Avraham S, Ophir D. Histopathology of the inferior turbinate with compensatory hypertrophy in patient with deviated nasal septum. Laryngoscope. 2000;110:2100-5.

15. Akoğlu E, Karazincir S, Balci A, Okuyucu S, Sumbas H, Dağli AS. Evaluation of the turbinate hypertrophy by computed tomography in patients with deviated nasal septum. Otolaryngol Head Neck Surg. 2007;136(3):380-4.

16. Zoumalan RA, Lebowitz RA, Wang E, Yung K, Babb JS, Jacobs JB. Flat panel cone beam computed tomography of the sinuses. Otolaryngol Head Neck Surg. 2009:140(6):841-4.

17. Lata S, Mohanty SK, Vinay S, Das AC, Das S, Choudhury P. "Is Cone Beam Computed Tomography (CBCT) a potential imaging tool in ENT practice? A cross-sectional survey among ENT surgeons in the State of Odisha, India. Indian J Otolaryngol Head Neck Surg. 2018;70(1):130-6.

18. Keleș B, Öztürk K, Ünaldı D, Arbağ H, Özer B. Is there any relationship between Nasal Septal Deviation and Concha Bullosa. Eur J Gen Med. 2010;7(4):359-64

19. Serifoglu I, Oz III, Damar M, Buyukuysal MC, Tosun A, Tokgöz Ö. Relationship between the degree and direction of nasal septum deviation and nasal bone morphology. Head Face Med. 2017;13(1):3.

20. Janovic N, Janovic A, Milicic B, Djuric M. Relationship between nasal septum morphology and nasal obstruction symptom severity: computed tomography study. Braz J Otorhinolaryngol. 2020. https://doi.org/10. 1016/j.bjorl.2020.09.004 (in press).

21. Al-Naqib L, Abdulla N, Karem SM, Mahmood SQ. Relationship between nasal septum deviation angle and it is effect on maxillary sinus volume in sulaimani population. Ind J Forensic Med Toxicol. 2020;14(2):992-5.

22. Codari M, Zago M, Guidugli GA, Pucciarelli V, Tartaglia GM, Ottaviani F, Righini S, Sforza C. The Nasal Septum Deviation Index (NSDI) based on CBCT data. Dentomaxillofac Radiol. 2016:45(2):20150327.

23. Javadrashid R, Naderpour M, Asghari S, Fouladi DF, Ghojazadeh M. Concha bullosa, nasal septal deviation and paranasal sinusitis; a computed tomographic evaluation. B-ENT. 2014;10(4):291-8.

24. Periyasamy V, Bhat S, Sree Ram MN. Classification of naso septal deviation angle and its clinical implications: a CT scan imaging study of Palakkad Population, India. Indian J Otolaryngol Head Neck Surg. 2019;71(Suppl 3):2004-10

25. Goergen MJ, Holton NE, Grünheid T. Morphological interaction between the nasal septum and nasofacial skeleton during human ontogeny. J Anat. 2017;230(5):689-700.
26. Yonis MA, Elgalil AS, Elshamy MI, Eldiehy IM. The relationship between Ethmoid roof, cribriform plate dimensions and degree of septal deviation angle. Egypt J Hosp Med. 2019;75(6):2993-9.

27. Altunay ZO. Volumetric computed tomography analysis of Middle Turbinate Aeration (Concha Bullosa) in Nasal Septal Deviation. Eur J Rhinol Allergy. 2020;3(1):10-2.

28. Shobeiri E, Salehi G, Jalalvandian A. Relationship between severity of nasal septum deviation and pneumatization of mastoid cells and chronic otitis media. J Babol Univ Med Sci. 2018;20(2):27-32.

29. Akay G, Yaman D, Karadağ Ö, Güngör K. Evaluation of the relationship of dimensions of maxillary sinus drainage system with anatomical variations and sinusopathy: cone-beam computed tomography findings. Med Princ Pract. 2020:29(4):354-63.

30. El-Anwar MW, Hamed AA, Abdulmonaem G, Elnashar I, Elfiki IM. Computed tomography measurement of inferior turbinate in asymptomatic adult. Int Arch Otorhinolaryngol. 2017;21(4):366-70.

31. El Shafei AA, Belih MA. Evaluation of nasal obstruction by measuring the thickness of inferior turbinate and nasal obstruction questionnaire. Int J Curr Res. 2017;9(8):55708-13.

32. El-Demerdash AA, Beheiry EA, El-Aini SM, Mohamed AS, Khattab AM. Morphological and histopathological study of hypertrophied inferior nasal turbinate in Egyptian patients: in clinical perspective. Egypt J Otolaryngol. 2020;36:24.

33. Khayat FJ, Mazhar H. Effect of septoplasty on inferior turbinate hypertrophy. Diyala J Med. 2012;2(1):21-9.

34. Kang JW, Yoo JB, Kim CH, Lee JG. Structural changes of inferior turbinate in patients with septal deviationsurgical: implication. J Rhinol. 2004;11(1, 2):40-3.

35. Tomblinson CM, Cheng MR, Lal D, Hoxworth JM. The impact of middle turbinate concha bullosa on the severity of inferior turbinate hypertrophy in patients with a deviated nasal septum. Am J Neuroradiol. 2016;37(7):1324-30

36. Berger G, Gass S, Ophir D. The histopathology of the hypertrophic inferior turbinate. Arch Otolaryngol Head Neck Surg. 2006;132(6):588-94.

37. Schmidt J, Zalewski P, Olszewski J, Olszewska-Ziaber A. Histopathological verification of clinical indications to partial inferior turbinectomy. Rhinology. 2001;39(3):147-50.

38. Baraniuk JN. Pathogenic mechanisms of idiopathic nonallergic rhinitis. World Allergy Organ J. 2009;2(6):106-14.

39. Bhandary SK, Kamath PS. Study of relationship of concha bullosa to nasal septal deviation and sinusitis. Indian J Otolaryngol Head Neck Surg. 2009:61:227-9

40. N42Stammberger H. Functional Endoscopic sinus surgery: the Messerklinger technique. Philadelphia: B.C. Decker; 1991:156-68.

41. Smith DH, Brook CD, Virani S, Platt MP. The inferior turbinate: an autonomic organ. Am J Otolaryngol. 2018;39(6):771-5.

42. Chen XB, Lee HP, Chong VF, de Wang Y. Numerical simulation of the effects of inferior turbinate surgery on nasal airway heating capacity. Am J Rhinol Allergy. 2010;24(5):e118-22.

43. Jourdy D. Inferior turbinate reduction. Operative Tech Otolaryngol. 2014;25(2):160-70.

44. Han JK, Stringer SP, Rosenfeld RM, Archer SM, Baker DP, Brown SM, Edelstein DR, Gray ST, Lian TS, Ross EJ, Seiden AM, Setzen M, Tollefson TT, Ward PD, Welch KC, Wise SK, Nnacheta LC. Clinical consensus statement: septoplasty with or without inferior turbinate reduction. Otolaryngol Head Neck Surg. 2015;153(5):708-20.

45. Lechuga L, Weidlich GA. Cone beam CT vs. fan beam CT: a comparison of image quality and dose delivered between two differing $\mathrm{CT}$ imaging modalities. Cureus. 2016;8(9):e778.

\section{Publisher's Note}

Springer Nature remains neutral with regard to jurisdictional claims in published maps and institutional affiliations. 